\title{
Tohoku rupture reloaded?
}

To the Editor - Tormann et al. ${ }^{1}$ evaluate changes in the $b$-value, a measure of the relative abundance of small and large earthquakes, as a function of space and time in northeast Japan. Near the high-slip zone of the 2011 magnitude 9 Tohoku-oki rupture, they document a sudden increase in the $b$-value at the time of the earthquake and its return to about $77 \%$ of its average 1998-2003 value within about two years. Assuming that the $b$-value is negatively correlated with differential stress ${ }^{2}$, they infer that the stress relieved by the earthquake has very rapidly recovered to levels found before the earthquake. Consequently, the authors propose that megathrust earthquake occurrences follow a Poisson process and are effectively random in time. However, we argue that the hazard of a great tsunami-producing earthquake in this section of the Japan megathrust zone is unlikely to already be almost as high as it was just before the 2011 event. Instead, many centuries of stress accumulation are required to rebuild stress and produce another great event.

Prior to the earthquake, the seismicity in northeast Japan was predominantly contractional and involved reverse faults (Fig. 1a,c). Since the Tohoku-oki earthquake, there have been few reverse events near the high-slip zone of the rupture (Fig. 1b,d) and aftershocks primarily occurred as extensional (normal faulting) events in both the overriding and downgoing plates of the subduction zone. The dominance of normal faulting suggests that the stress drop during the mainshock was large enough, relative to the background stress, to reverse the style of faulting near the high-slip zone ${ }^{3,4}$. Because events with different faulting types in northeast Japan have different $b$-values (Supplementary Information), we suggest that the observed coseismic rise and postseismic decay of $b$-values (Fig. 1f) partly reflect the fact that Tormann and colleagues sampled event populations with different mechanisms and from different source volumes in the subduction zone (Fig. 1e).

Tormann and colleagues argue that reloading of stress caused by rapid postseismic deformation processes, complemented by fault healing processes and stress-field homogenization, may quickly re-establish compressional stress levels to those found just before the earthquake. However, although reloading of a megathrust rupture is indeed most rapid during the early period of postseismic relaxation, our models of stress recovery constrained by geodetic and seismicity data suggest that only a very small fraction of the approximately $10 \mathrm{MPa}$ coseismic stress drop in the high-slip zone could have been recovered in the first three postseismic years. Even when considering the contributions from multiple sources of postseismic deformation ${ }^{5}$, the average shear-stress changes near the high-slip zone only amount to less than 0.5 MPa within three years and approach $1 \mathrm{MPa}$ after relaxation of coseismic stress perturbations more than two decades later (Fig. 1g). Completion of the transient relaxation together with loading from steady plate convergence allow for full shear-stress recovery within several hundred years (Supplementary Information).
In summary, we suggest that the temporal changes of $b$-values near the highslip zone of the Tohoku-oki earthquake may reflect sampling of earthquakes from different volumes and fault populations in the subduction zone. Furthermore, postseismic relaxation processes are not capable of rapidly reloading the fault. Although the spatial and temporal variations of $b$-values are intriguing, it appears premature to assume $b$-values as a direct proxy for stress on the Japan subduction thrust and to argue for general randomness of megathrust earthquakes based on this observation.

\footnotetext{
References

1. Tormann, T., Enescu, B., Woessner, J. \& Wiemer, S. Nature Geosci. 8, 152-158 (2015)

2. Scholz, C. H. Geophys. Res. Lett. 42, 1399-1402 (2015).

3. Hardebeck, J. L. Geophys. Res. Lett. 39, L21313 (2012).

4. Hasegawa, A., Yoshida, K. \& Okada, T. Earth Planets Space 63, 703-707 (2011).

5. Hu, Y., Bürgmann, R., Uchida, N., Banerjee, P. \& Freymueller, J. T. J. Geophys. Res. Solid Earth http://doi.org/bbtk (2016).

6. Yagi, Y. \& Fukahata, Y. Geophys. Res. Lett. 38, L19307 (2011)
}

Additional information

Supplementary information is available in the online version of the paper.

Roland Bürgmann ${ }^{1 \star}$, Naoki Uchida ${ }^{2,3}$, Yan $\mathrm{Hu}^{1}$ and Toru Matsuzawa ${ }^{2}$

'Department of Earth and Planetary Science and Berkeley Seismological Laboratory, University of California, Berkeley, California 94720, USA.

${ }^{2}$ Graduate School of Science, Tohoku University, Sendai 980-8578, Japan. ${ }^{3}$ International Research Institute of Disaster Science, Tohoku University, Sendai 980-0845, Japan.

*e-mail: burgmann@berkeley.edu

\section{Reply to 'Tohoku rupture reloaded?'}

Tormann et al. reply - We agree with Bürgmann and colleagues' comment that additional parameters might play a role in explaining and interpreting the observed changes in $b$-values, such as the suggested activation of different faulting regimes. Maps of $b$-values always represent volumetric averages and are generally prone to missing shifts of origin locations within the sampled rock volume. However, we reduced this limitation by using distanceweighted sampling of events ${ }^{1,2}$, which accounts for the relative hypocentre/plate interface distance and focuses on processes along the interface.

Bürgmann and colleagues select earthquakes with a variance reduction of greater than $80 \%$ from the F-net seismic catalogue. However, the variance reduction changes significantly with time and specifically decreases after the Tohoku-oki earthquake. Thus the selection process biases the catalogue by excluding a third of pre- and more than half of post-Tohoku-oki events, independent of event magnitude (30\% post-Tohoku-oki for variance reduction of greater than $70 \%)$. In our view, the relative fractions of mechanism types (and their $b$-values) cannot be established with confidence from these subsets.

Aside from these doubts, the $b$-value time series that Bürgmann and colleagues infer from the relative mechanism fractions reproduces our documented mainshock-related $b$-value increase ${ }^{1}$ with smaller amplitude. The inferred smaller amplitude is consistent with the range of $b$-values observed between different 
a

March 1997-11 March 2011

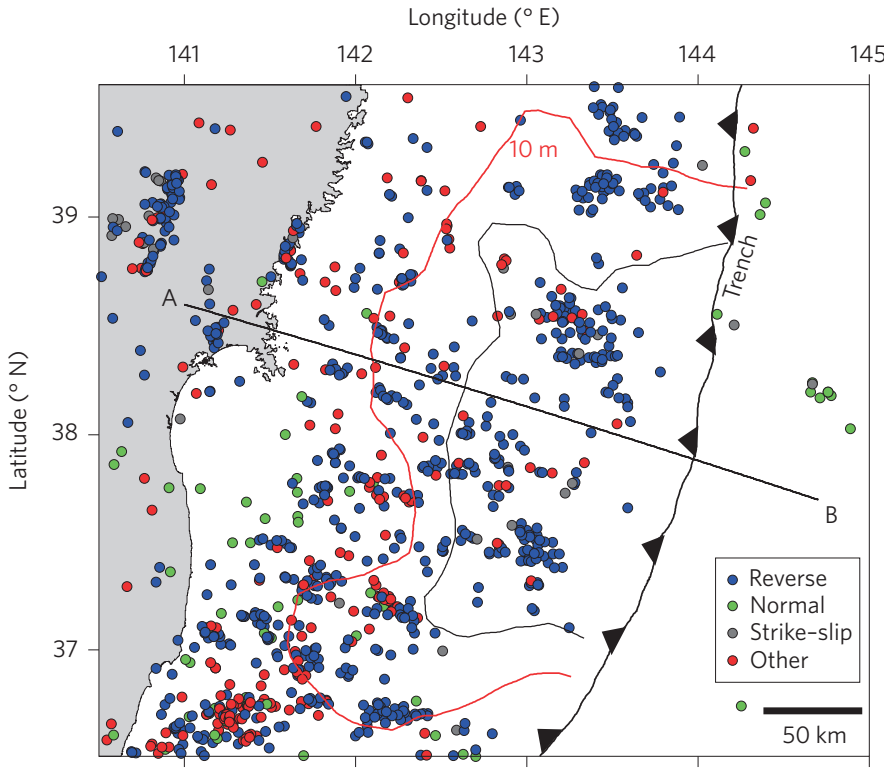

b

12 March 2011-April 2015 c

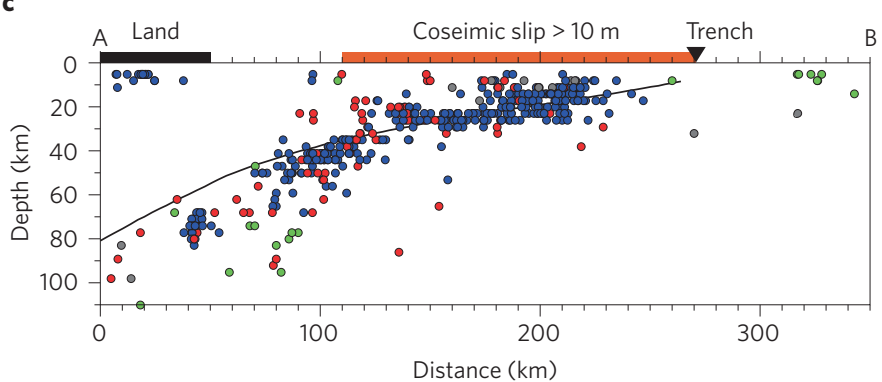

e
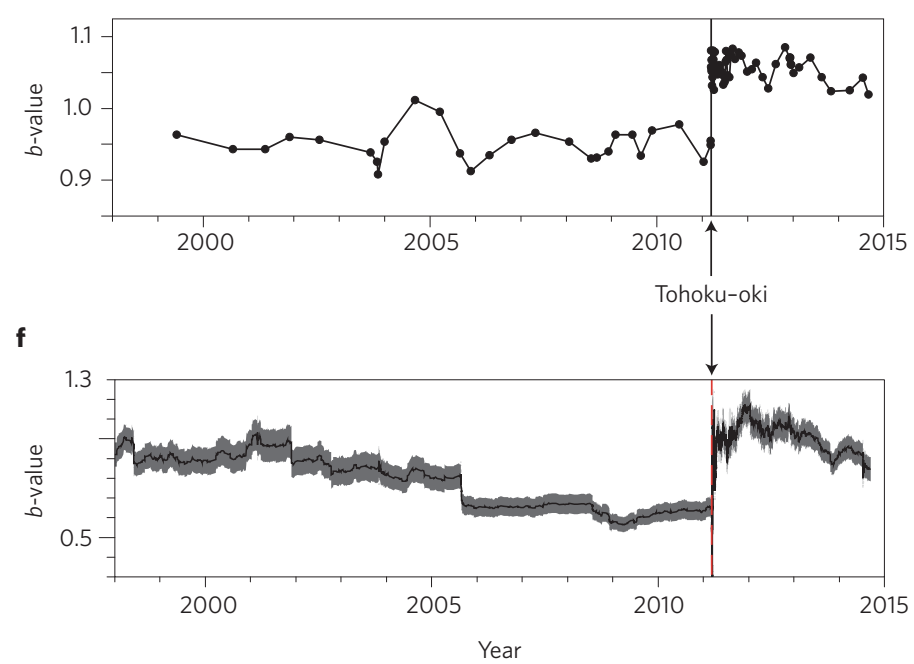

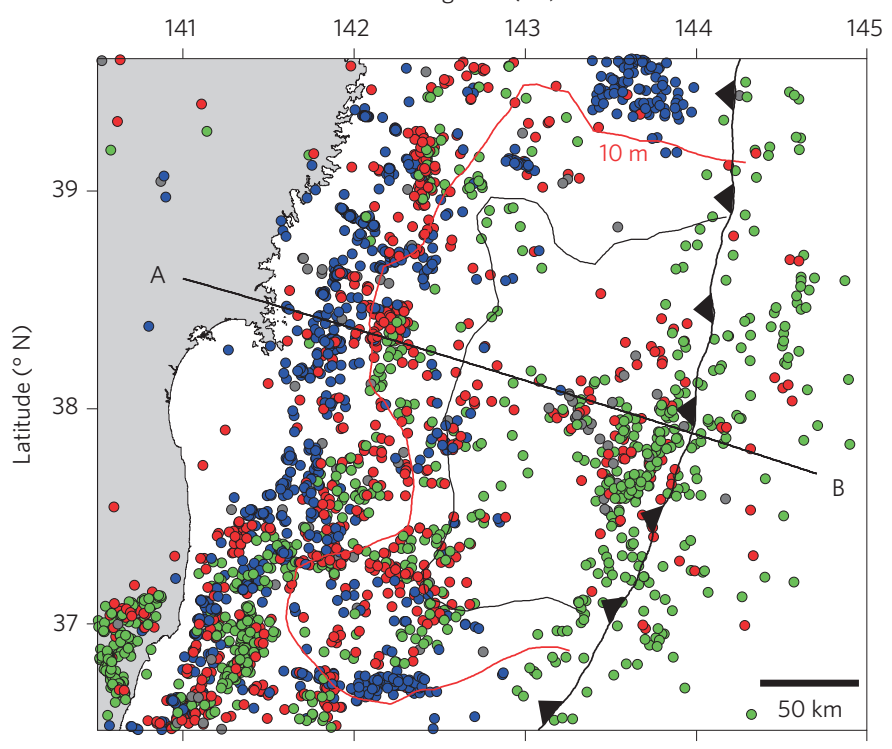

d

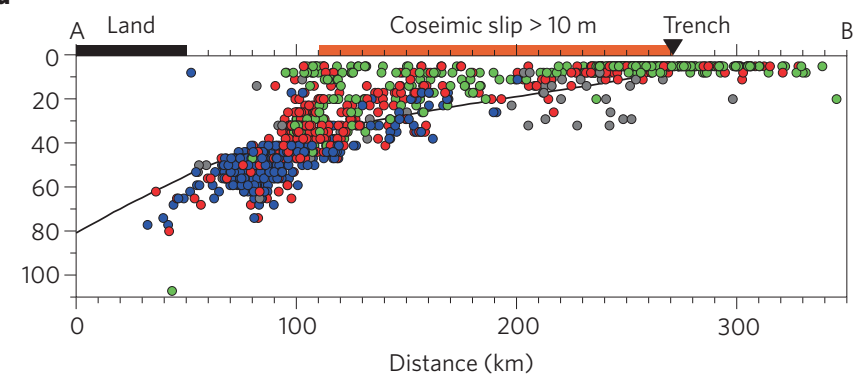

g

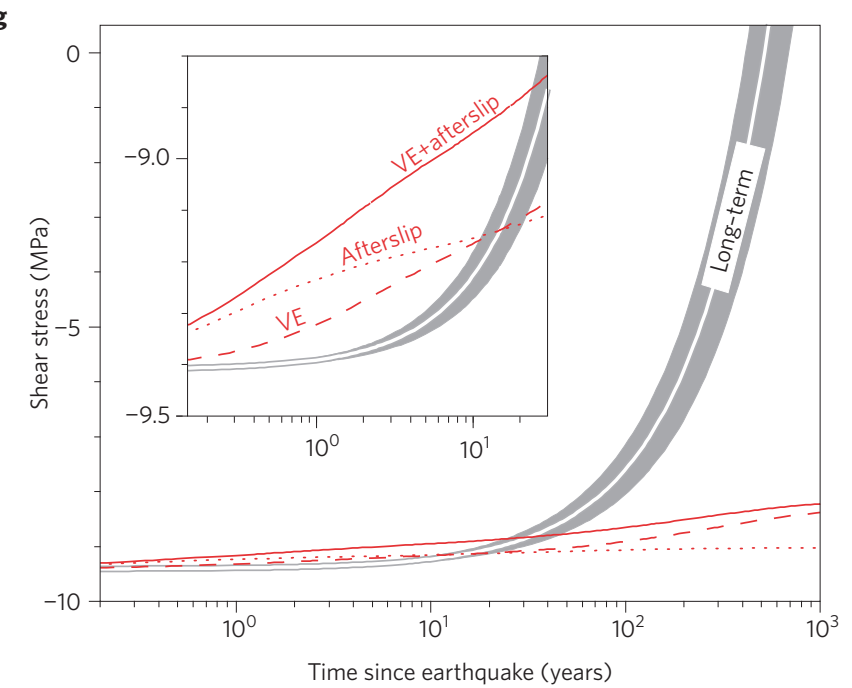

Figure 1 | Distribution of focal mechanisms, time series of the $b$-value and modelled stress changes. $\mathbf{a}, \mathbf{b}$, The distribution of F-net seismic catalogue focal

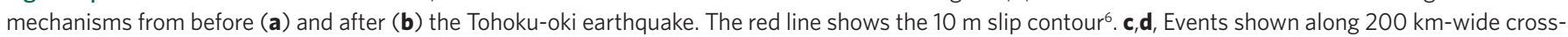

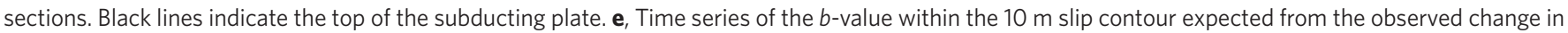

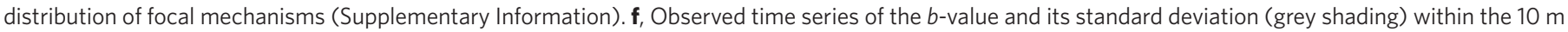

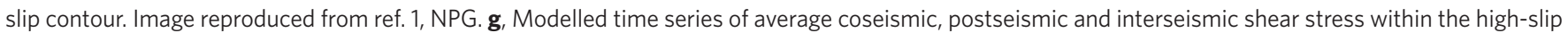

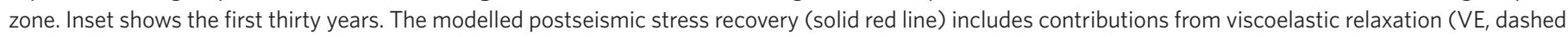

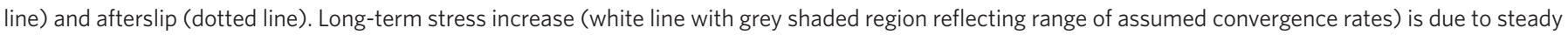
plate convergence about the locked high-slip zone. 